\title{
An Ethnographic Study of Diabetes: Implications for the Application of Patient Centred Care in Cameroon
}

\author{
Paschal Kum Awah ${ }^{1,2}$ \\ ${ }^{1}$ Department of Anthropology, Faculty of Arts, Letters and Social Sciences, University of Yaounde I, P.O. Box 755, Yaounde, Cameroon \\ ${ }^{2}$ Centre for Population Studies and Health Promotion, P.O. Box 7535, Yaounde, Cameroon \\ Correspondence should be addressed to Paschal Kum Awah; awahpaschal@yahoo.fr
}

Received 31 March 2014; Revised 16 June 2014; Accepted 6 August 2014; Published 26 August 2014

Academic Editor: Benjamin Campbell

Copyright (c) 2014 Paschal Kum Awah. This is an open access article distributed under the Creative Commons Attribution License, which permits unrestricted use, distribution, and reproduction in any medium, provided the original work is properly cited.

\begin{abstract}
Participant observation was conducted to explore the understanding of diabetes and examine the implications of these understandings for providing effective patient centered care in Cameroon. Ethnographic techniques-content and thematic analysis - were used to analyze the data collected from diverse techniques. Most participants distinguished "natural," "supernatural," and "man-made" causes of diabetes. Such aetiologies guided the behaviour and approaches adopted for treatment and helped explain why biomedical and traditional healing frameworks could so readily be used in tandem. Clinical encounters are often only one small part of the diabetes care process, alongside recourse to traditional medicine. With rituals, agents causing diabetes are apparently more convincingly explained as powerful reinforcement and a cure promised in traditional medicine. Though it seems "irrational" and dangerous to clinics when patients alternate between therapeutic regimes or pursue both simultaneously, it seems perfectly rational and beneficial to patients and beyond. So long as biomedical practitioners fail to recognize that their patients will probably also have recourse to traditional medicine, they and their services may compound the problems they face for patients to discuss openly how they have been managing their condition.
\end{abstract}

\section{Introduction}

Although sub-Saharan Africa remains afflicted by very high rates of communicable diseases, noncommunicable diseases occur at age specific rates above those found in rich countries, such as those of Western Europe and North America [1]. Diabetes is still relatively uncommon in rural areas but is becoming prevalent in urban areas, affecting about $5 \%$ of adults in urban Tanzania [2] and 5.8\% in urban Cameroon [3]. WHO estimated in 2000 that the prevalence of diabetes for all age groups worldwide was to be $2.8 \%$ in 2000 and $4.4 \%$ in 2030 [4]. WHO estimated that 347 million people, worldwide, had diabetes in 2013 [4]. The organization had estimated that the total number of people with diabetes is projected to rise from 171 million in 2000 to 366 million in 2030. These statistics are further confounded by those of the International Diabetes Federation (IDF) which hold that today there are 382 million people living with diabetes. A further 316 million with impaired glucose tolerance are at high risk of the disease-an alarming number that is set to reach 471 million by 2035 [5]. Further, it is estimated by IDF that, by the end of 2013, diabetes will have caused 5.1 million deaths and cost USD 548 billion in health care spending. Without concerted action to prevent diabetes, in less than 25 years' time there will be 592 million people living with the disease. Most of those cases would be preventable.

However, without a multisectoral, all-of-society approach, the disturbing projections will be realized [5]. The prevalence of diabetes is higher in men than women, but there are more women with diabetes than men. The urban population in developing countries is projected to double between 2000 and 2030. The vast majority of this increase will occur in men and women aged 45 to 64 . It is likely that WHO and IDF projections are highly conservative. They take into account trends in population growth and in urbanization but fail to properly account for trends in risk factors, particularly increasing levels of obesity and changing dietary patterns. The emergence of HIV/AIDS and their ongoing therapies show that the emergence of diabetes is associated with HIV/AIDS, given that some of the treatment options favour exposure to 
diabetes. Several studies have found an association between taking these medications and increased rates of type 2 diabetes [6]. While the number of people with diabetes is growing rapidly in urban Africa, health systems remain wholly unequal to this challenge, being poorly organised and very poorly resourced $[7,8]$. However, even with low levels of resources there is evidence that with the right training and organisation a substantial proportion of diabetes related complications are preventable. Another issue related to illprepared hospitals and medical staff is that they have mostly been trained to treat infectious diseases and that is what they have been treating for years. They have not had the training or experience in treating chronic diseases like diabetes. Most of the human resources for health in sub-Saharan Africa have been ill-equipped to manage cases of diabetes and diabetes risk factors. It has been suggested that priority should be given to blood pressure control, moderate blood glucose control, and foot care and that these are highly cost effective, even cost saving [9].

However, there is an ongoing debate about the contribution of other health care partners, like traditional healers (TH), in chronic disease care in Africa. This has been very topical in South Africa where they have been pulled in and trained to educate people about HIV/AIDS $[10,11]$, a means of neutralising their claims of having a cure for it. Similar claims are rife with diabetes and until this group of health care providers is made to understand that there is none, there will always be problems of tackling diabetes from the public health perspective. Though there is a service in the Cameroon Ministry of Public Health created to respond to issues related to the practice of traditional medicine, the South African situation of integrating traditional healers into the mainstream health system does not obtain in Cameroon. Even though some wilful initiatives are being undertaken, there is very little evidence to indicate how useful they may be in providing psychosocial support and other culturally grounded care to patients and families of diabetes [12-14]. We looked at a wider group of people but De-Graft Aikins [15] concentrated on patients, therefore limiting the scope of appraisal. Explaining the role of another group of healers widens the understanding of the scope of the healing landscape. This paper further provides additional explanations of WHO's Innovative Care for Chronic Conditions Framework $[16,17]$. This WHO framework extended the scope of care to the communities but failed to consider treatment outside the realm of biomedicine.

WHO's Innovative Care for Chronic Conditions Framework [16, 17], based on the Chronic Care Model [18], provides health system wide guidance on what needs to be in place to deliver effective chronic disease care. At the heart of this framework are the provision of patient centred care and the empowerment of patients. Effective chronic disease care is seen as requiring a partnership between patients, their family, community, and their biomedical health carers. We report here the findings of an ethnographic study of people with diabetes, their families, communities, and health carers including traditional healers in Cameroon. Traditional healers' role seems neglected, yet it is important when holistic care is considered. Acknowledging the role of traditional healers alongside other care providers is acknowledging the importance of the cultural ecology of people with diabetes. Our aim is to explore the understanding of diabetes and examine the implications of these understandings for providing effective patient centred care in Cameroon and similar settings within Africa. The data for this study is ten years old but the findings are still valid as diabetes and diabetes risk factors are still on the increase in Africa and will double by 2030. Many countries including Cameroon have not yet set diabetes as priority on their health agenda so there is need to draw attention of governments and their development partners on cultural issues related to diabetes. This may provide evidence for action and compel government to act following the evidence from this study.

\section{Methods}

2.1. Settings. The study setting compared two health districts: one urban and one rural, located in Yaounde, Cameroon's capital, and Bafut, in Northwest Cameroon, respectively. In these districts, eight primary health care units were selected from which diabetes patients sought care. Tertiary care diabetes centres in Yaounde also formed part of the patients' treatment networks. The study took place over a 25 -month period from June 2001 to June 2003, with twelve months of ethnographic fieldwork in each place.

2.2. Ethnographic Methods. Ethnography entails the intensive study of people in their cultural contexts; it aims to build detailed descriptive accounts of social life and culture integrating several qualitative methods $[19,20]$. This method has been the hallmark of anthropologists' fieldwork, developed first in studies of "nonwestern" cultures and studies of subcultures within western societies, but is now used increasingly widely in several of the social sciences. In contrast to conventional scientific methods, ethnography is rarely experimental or predictive in aim; instead its rationale is to avoid reductionism by building up rounded descriptions from the flow of daily life, in order to highlight complexity in the multiple and often competing perspectives displayed in any social milieu. Rather than looking at a small set of variables and a large number of subjects ("the big picture"), the ethnographer attempts to create a detailed understanding of the circumstances of a relatively few people being studied intensively $[19,20]$. For this study, observations, conversations, interviews, focus group discussions, biographies, case studies, and documentary evidence were the range of tools used in fieldwork. Table 1 summarises the methods that were used in this study and the number of observations made.

2.3. Participants. Twenty patients and their families, ten each in Yaounde and Bafut, were selected for close follow-up. Eight families were visited more or less daily over extended periods; the rest were visited weekly, sometimes more than once. This was more intensive in the rural than in the urban district. The mean number of family members was seven. The duration of visits ranged from 30 minutes to two 
TABLE 1: Matrix of methods used in participant observation during 25 months of fieldwork.

\begin{tabular}{|c|c|c|}
\hline Method of data collection & Brief description of method & Number/episodes and participants \\
\hline Daily observations & $\begin{array}{l}\text { A research method, in which the investigator systematically } \\
\text { watches, listens to, and records the phenomenon of interest. A } \\
\text { research method in which the investigator takes part in the } \\
\text { social phenomenon of interest by participating with a group and } \\
\text { observing the interactions between them and between the } \\
\text { researcher and subjects to achieve a greater understanding. } \\
\text { Used in ethnographic approaches. This entails observing clinical } \\
\text { encounters and activities of groups and individuals and at times } \\
\text { participating actively. }\end{array}$ & $\begin{array}{l}\text { Numerous observations of } 20 \text { patients } \\
\text { within their families and community }\end{array}$ \\
\hline Clinic observations & $\begin{array}{l}\text { Observing and participating in clinical encounters and other } \\
\text { activities going on in clinics. }\end{array}$ & $\begin{array}{l}\text { Over clinical encounters in four clinics } \\
\text { with } 200 \text { patients in more than } 300 \\
\text { encounters. }\end{array}$ \\
\hline Case studies & $\begin{array}{l}\text { A research method which focuses on the characteristics, } \\
\text { circumstances, and complexity of a single case, or a small } \\
\text { number of cases, often using multiple methods. The case is } \\
\text { viewed as being valued in its own right and whilst findings can } \\
\text { raise awareness of general issues, the aim is not to generalise the } \\
\text { findings to other cases. Heritage \& Atkinson (1984) }\end{array}$ & 18 \\
\hline Biographies & $\begin{array}{l}\text { Information provided by an individual or groups of people, } \\
\text { tracing their life events and how they coped with diabetes }\end{array}$ & 18 \\
\hline Fieldwork conversations & $\begin{array}{l}\text { The central goal of was the description and explication of the } \\
\text { competence that ordinary speakers use and rely on in } \\
\text { participating in intelligible, social interaction. At its most basic, } \\
\text { the objective was one describing the procedures by which } \\
\text { fieldwork conversations amongst participants produce } \\
\text { knowledge of processes that build around diabetes care. }\end{array}$ & Daily as situations permitted \\
\hline In-depth interviews & $\begin{array}{l}\text { The research method involved asking questions from an } \\
\text { interview guide and tape-recording participants' replies. This } \\
\text { was recorded by the researcher writing down answers verbatim } \\
\text { and summarizing the findings allowing data analysis to be } \\
\text { conducted later }\end{array}$ & 34 \\
\hline $\begin{array}{l}\text { Focus group discussions } \\
\text { (FGD) }\end{array}$ & $\begin{array}{l}\text { A qualitative technique developed by social and market } \\
\text { researchers in which 6-12 individuals are brought together and } \\
\text { interactively give their views and impressions upon a specified } \\
\text { topic. (Morgan 1992). These were used to evaluate attitudes } \\
\text { towards the topic. Focus groups conducted in this study were } \\
\text { usually homogeneous with members being generally of the } \\
\text { same age, gender, and status to encourage participation }\end{array}$ & 27 \\
\hline Documentary evidence & $\begin{array}{l}\text { Using documents to get information to complement what other } \\
\text { methods cannot provide. Clinical and handheld records of } \\
\text { patients were used in this fieldwork. }\end{array}$ & $\begin{array}{l}\text { Observation of clinical records and their } \\
\text { use at the same time as observation of } \\
\text { clinical encounters }(>200)\end{array}$ \\
\hline
\end{tabular}

hours. Meanwhile, more than two hundred patients were part of the network of observations in the clinics and in the communities where they lived. That is, all patients at the sampled clinics formed part of the observation network within the clinic during consultation sessions and out of the clinical settings. Ten traditional healers were the main frame of traditional healers observed regularly, at least daily for some and biweekly for others. Twenty-four diabetes consultants were the main biomedical health care providers (BHCP) observed in clinical encounters, though the activities of others within these care units were closely monitored. The wider communities of these health districts were part of the daily fieldwork observation. Table 1 provides details of the matrix of methods used for fieldwork.
2.4. Procedures and Ethics. An ethical clearance was obtained from the National Ethical Committee of Cameroon and authorisation to conduct the study from the Ministry of Scientific Research. All health care providers formed part of the units of observation but those caring for diabetes patients were the main focus. Patients were identified and selected in diabetes clinics. The consent of fieldwork participation was sought as to whether participants would accept being observed in clinical encounters and in their homes. Once they accepted, patients were observed in the clinics and later in their families and communities. While in the families the consent of family members was equally sought. Informed consent was documented on print for patient and health care providers and in audiotapes and orally for other participants. 
Observations in the families gave insights into treatment networks beyond the clinic, leading us to traditional medicine and traditional healers.

Aspects of the daily lives of patients, family members of patients, traditional healers, health care providers, and the wider community were the focus of the ethnographic fieldwork. Participation was moreover sustained simply by "being there," on hand to take part in family or community events, or to engage in conversations with whoever was present in a variety of contexts, extending well beyond what might be considered as strictly health related. This was particularly the case in the rural context of Bafut.

\subsection{Data Management and Analysis}

2.5.1. Transcribing of Tape-Recorded Data and Completing of Fieldnotes. All tape-recorded materials of conversations, interviews, and focus group discussions were transcribed and fieldnotes completed for all observations, conversations, biographies, and case studies. Documentary evidence was summarised from clinic and patient held records.

Time was spent listening and transcribing recorded interviews and focus group discussions. Fieldnotes taken in the course of observations were completed. The transcripts and documentary evidence were typed into word processing software. The transcripts captured features of conversations such as emphasis, speed, tone of voice, timing, and pauses. These elements made up the crucial aspect of interpreting data, given the multiple events that produced them. The data from transcripts were read transcript by transcript. Reading and completing the transcripts and making notes from them permitted us to identify ideas, make observations, and get insights and inferences. I organized the data and sorted out all the materials needed to enable getting on with the initial analysis. All transcripts were labeled with file names, typed in a word processing package, and stored using these file names. Once each transcript was read and classified, it was dissected, pulled apart, and scrutinized transcript by transcript to enable the full understanding of the nature of the data we were collecting.

2.5.2. Coding. The coding process was a mechanical way of assigning names to portions of text. The coding involved reading through the data, identifying themes and patterns, and placing them under headings or brief descriptions summarizing what they mean. Sections of text that related to a code were cut and pasted into the document created to represent that code as we worked through each transcript. It enabled us to build up a logbook of relevant text related to each created code. The source of each text that is collated to the codes was labelled so that I could easily refer back to it and understand the context in which the text was produced. Some text fitted within more than one code. In the first reading of transcripts, the codes were general. Subsequent reading enabled the splitting of the general codes into more specific ones. Through the coding process, similar portions of data were pulled together. Codes provided a fast snapshot of similarities, differences, patterns, themes, categories, concepts, and relationships from huge amounts of data sets across transcripts. The codes permitted the linking of initial transcripts and fieldnotes to subsequent ones. These codes were the main emerging ideas from the data.

Computer software was not used to code data. Rather manual coding using both pen and paper to code manual transcripts was conducted and the computer to code electronic transcripts. A logbook of codes was developed and stored electronically and manually. We wanted to try an experience that could be documented and shared with people who do research in settings with limited access to technologies that can facilitate data management.

A multistage analysis was done by sorting and pulling the themes together and verifying them to get emerging details. The analysis draws a bit on Garfinkel [21] but the fieldwork sought to build confidence with the participants without considering his approach. The analysis approach is a combination of ethnomethodologies but with greater emphasis on grounded theories emerging from the data. Hence, content and thematic analyses form the basis of the data management and analysis. The analyses were overlapping multiple stages. The data were divided into several groups differing in depth. Further processing of data was done to identify themes from the contents of texts and probing into the meanings of the themes. Each stage was repeated over and over as the data collection process evolved. Data analyses began at the moment the first transcripts of fieldnotes from observing clinical consultations were available through the fieldwork process and intensified after fieldwork.

The analyses comprised a primary analysis stage and profound analysis stages, with supplemental data collected at subsequent stages, then further analysis. The primary analysis for this study included preliminary recognition of broader themes and the subsequent detection of themes and subthemes that required more precise analysis. This widened the meanings inherent in texts to overcome any distortions. At the primary analysis stage, the analysis of themes and the development of concepts were established with more accuracy. The profound analysis stage in this ethnography included repeating recognition of themes considering the dynamics that followed subsequent data collection and subsequent analysis. The contents of transcripts were reviewed and analyzed as data collection continued. This process permitted the amendment of the questions that were asked to enable more data gathering as fieldwork evolved. This stage took into account the supplemental data obtained at the previous and subsequent stages of fieldwork. It enabled the detecting of themes that required more precise analysis and the identification of dynamics in themes and concepts leading to the collection of supplementary data. These analyses gradually built up into a theory grounded in the data from which the themes and concepts emerged.

The themes and concepts revealed relationships and differences in themes according to the categories of research participants. A logbook about the themes was kept alongside the transcripts. With the logbook we started having an emerging story that revealed ideas, more insights, and explanations. The themes in the logbook were followed up in subsequent fieldwork activities to look for alternative 
explanations and evidence to support the ideas and interpretations. Further fieldwork permitted the verification of the themes and the identification of new themes and subthemes as well as evidence that might not support them. The reading of transcripts and comparing of themes and subthemes were done several times until a point where it made sense was reached and arguments were produced that addressed the research objective.

The analysis led to obtaining lay definition of the concept of diabetes and how the lay definitions influence the way people seek diabetes care. The definitions are grounded in people's thoughts and behaviour as revealed by the ethnography. The shifts in meanings illustrate a multistage profile that provides the possibility of organising a pattern-matching mechanism that permits the display of the structure of quoted expressions and their actions into minute component subparts of actors involved in diabetes experiences and diabetes care in Cameroon.

2.5.3. Visual Data. This paper is a guide to practical and theoretical considerations for researchers new to qualitative data analysis. Data examples are given to illustrate decisions that were made when transcribing or assigning the task to others. Verbal and nonverbal interactions together shape communicative meaning [17]. The study illustrates the validity and necessity of visual information for data interpretation. For example, clinical observations in health facilities and traditional healing clinics illustrate that room layout, body orientation, facial expression, gesture, and the use of equipment in consultation increase the element of trust in each of the health care systems as was done in Greatbatch et al. [22] study. However, visual data are more difficult to process since they take a huge length of time to transcribe and for the meanings emerging from them to be sought, and there are fewer conventions for how to represent visual elements on a transcript [23].

\section{Results}

The journey of studying the treatment of diabetes started with patients at the clinics and followed through to their homes and the wider community where family members and traditional healers emerged as key partners in providing support for diabetes care. The understanding of diabetes by each of these key partners and their role in seeking care is critically reviewed within the patient centred care model. Patient centered care is defined as an approach to "providing care that is respectful of and responsive to individual patient preferences, needs, and values and ensuring that patient values guide all clinical decisions" [24]. Patient centered care that encompasses informed decision making can improve treatment choice, quality of care, and outcomes. It recognizes the need for major changes in the process of care that arranges health care systems around the patient [25]. Though many actors are involved in the healing process of people with diabetes, each plays a role of assistance and not taking over the responsibility of care. The next sections of the findings present the dynamics involved in caring for diabetes by different actors involved in the triangle of care for people with diabetes.
3.1. Patients. In seeking to understand how people with diabetes and their immediate families make sense of this condition, an ethnographic approach starts from the categories and distinctions made by those studied. A fundamental distinction here concerned aetiology as illustrated by the following quote below.

"...My diabetes was caused by beer. I was drinking
sweet beer which I could sit at a time and take
eight bottles. I was advised against that but I did
not know. They would say, "as you are drinking
beer like this you would soon develop diabetes." I
didn't know what diabetes was. I started drinking
glucose. After some time, I started urinating very
frequently, but thought that it was a way of
cleaning my system. I didn't know that I was
adding sick, until when diabetes was discovered.
... (Saah, diabetes patient in Bafut)."

Aetiologies emerged from patients, family, and community members as fieldwork evolved and built up into three distinct categories of diabetes developed by fieldwork participants. The categories could be overlapping at one point but gradually narrow down to mean one thing and at the same time stay connected to other categories of aetiologies, as the aetiologies about a patient's diabetes were shaped and reshaped. These categories are called "natural" (i.e., lifestyleinduced) diabetes, "ancestral" (i.e., ancestor-caused) diabetes, and "man-made" (i.e., witch-induced) diabetes.

3.1.1. Natural Aetiology. Natural causes are explained in terms of lifestyle. Sugar and sweet things in general seem to be one of the causes of diabetes that people highlight and understand, reflecting how the language of "high sugar level" (hyperglycaemia) in the clinic found its way into popular idioms. Most people with diabetes, irrespective of social status, often declared, "I know that eating a lot of sweet things causes diabetes. This one is natural." This kind of causation places the "blame" or responsibility on the individual for excesses in eating and drinking, and some people with diabetes by and large realise that this is the implication. Alcohol, high fat food, physical inactivity, obesity, and overweight are seldom considered as lifestyle risk factors of developing diabetes but rather valued as indicators of affluence. Advice on diet and alcohol consumption is not seen as straightforward and easy to follow. As a person with diabetes participating in a death celebration puts it,
"We are told not to drink palm wine, but this palm wine is medicine to us. When we drink we eat achu soup to neutralise the palm wine." (Sham, diabetes patient in Bafut)

This person with diabetes infers that palm wine is medicine, though as a beverage it may be a risk factor to diabetes and also interferes with the outcomes and quality of care for diabetes. Sham, in another way, acknowledges that a person with diabetes may self-inflict his own diabetes through diet. 
3.1.2. Supernatural Aetiology: Ancestors. A second causal framework is the supernatural ancestors. The ancestral framework, cuts across many areas in Cameroon as ancestral punishment, by way of illness, has pride of place in people's understanding of why illness strikes one person rather than another at any time. Ancestral interventions to "cause" diabetes are not always thought of as being attributable to recent oversights or human failings. When a person within a family develops diabetes, a diviner may trace the precipitating problem back to several generations, perhaps even a century or more. Most patients may ironically also interpret a family history of diabetes as a kind of family inheritance (created in this idiom by an unrealised and unresolved problem, dating several generations back). It is believed that ancestors can be appeased through rituals and a cure for diabetes obtained both traditional medicine and biomedicine. Taking treatment action needs meditating around the cause as revealed by a patient,

"When you are told that your ancestors have caused your diabetes, you have to accept and appease them with rituals, else you will waste all your time and resource in vain in the hospital and you will never be cured." (Amoni, diabetes patient in Yaounde)

Amoni emphasizes the power of supernatural agentsancestors-in causing diabetes and prescribes rituals as the starting point to care for diabetes caused by ancestors. Success in caring for such diabetes in the health facilities can only occur after rituals have been performed to clear the way.

3.1.3. Man-Made Aetiology. Witchcraft is the third widespread explanation for diabetes (among a long list of chronic health problems potentially attributable to the action of witches). Witchcraft is known as man-made diabetes. This might be represented in several ways:

"...A witch had sex with me while I was asleep. Since then, I developed a malaise until I was diagnosed with diabetes." (Jacob, diabetes patient in Bafut).

“...My friend sent this diabetes to me as Musong (unidentified symptoms), just because he was jealous of my progress..." (Prosper, diabetes patient in Yaounde).

The first remark highlights one of the commonest ways in which people assume that they might be vulnerable to witchcraft, namely, through sex as a route of transmission and an idiom of the body being breached, both for men and women. Part of the common currency of popular discussion about diabetes is to question why the clinics, with all their sophisticated technology, can only control diabetes, when a cure is potentially available in the traditional system of medicine. This is one aspect of a public cultural code in which "curing" is tacitly the goal of all treatments and calls into doubt the scientific efficacy of modern clinical medicine as illustrated by the following two extracts:
"Tailor. Frankly speaking, as soon as you will not know what is happening to you, you will go anywhere to grasp anything to obtain a cure.

Sammy. ...One turns round like this because there is no way. You want where you can be cured, because the clinics are unable to offer one." (Extract of Focus Group Discussion with diabetes patients).

The two quotes above explain why people with diabetes seek other alternatives of care. From the three categories of aetiology, the natural aetiology is framed around blaming the self as responsible for the occurrence of diabetes. The man-made aetiology whose explanation is framed around witchcraft and witchcraft practices blames an external human agent responsible for the occurrence of diabetes. The explanation of the supernatural aetiology links the cause to ancestors supernatural human agent believed to exist outside the immediate human world, which can cause harm and repair damage.

3.2. Family and Community Support. Diabetes is rarely simply an individual matter, to be handled by the patient alone. It is essentially a family one but also extends to encompass the wider community as illustrated by the following fieldnote:

"John developed diabetes coma. While nurses and doctors were restoring him, his family went to consult a diviner. The diviner told them that the ancestors were unhappy with him and had decided to punish him. A consensus was reached that ancestors had to be appeased by a ritual. When John recovered from the coma, he was informed and was amazed at the turn of events. However, he admitted that there was a rite which he failed to perform in his father's compound, when he was enthroned." (Fieldnotes in Bafut, 14 December 2002).

Families have to face big challenges when one member is diagnosed as a person with diabetes, notably concerning diet, alcohol, and money because they share the same beliefs with patients. One dilemma revolves around the pros and cons of cooking separately to reflect different dietary constraints as this quote illustrates:

“...We separate the cooking of food at home to make sure that he eats what his doctor prescribes... At times, we cook food in the same pot, remove his then add oil and salt in ours..." (spouse of a person with diabetes).

As with patients, most people also understand that excess consumption and presence of sugar in the body cause diabetes. The emphasis on the destructive power of sugar opens the way for higher alcohol consumption, which is seen as a neutralising agent, as a medicine to "cure" diabetes and complications like sexual dysfunction. This approach is not restricted to households with diabetes patients but 
extends to others who have a notion of diabetes. A number of patients resist the idea of dietary curbs and therefore come into conflict with family members who seek to impose clinic advice about diet.

3.2.1. Diet and Alcohol. But of course all this could work the other way around, for there are instances where people with diabetes are unhappy with family reluctance to provide the appropriate diet, typically on grounds that the extra cost is too great. The consequence can easily be a feeling of a lack of care and a resulting mutual resentment. Ensuring that the person with diabetes remains healthy is usually seen as a shared family responsibility. But the ideal is not necessarily realised in practice, and there is often considerable tension between spouses and parents and children, particularly where one is felt to be undermining the efforts of the other through blame. Dietary and alcohol issues are proven to be even harder to deal with outside the home in public socialising and festive communal occasions. If diet provokes argument, alcohol does so even more as a diabetic explained in this quote, "My friends do not more want to go out with me because I drink Soda Water. They tell me to stay at home and be doing that."

\subsubsection{Pressures on Social Mores and Health Care Alternatives.} Sex also is quite commonly an area of considerable difficulty between most husbands and wives. Diabetes can easily compound these general pressures of urban social mores, as possible complications of the disease arise and as libido declines, as this quote explains.

"...The fact that I have lost my manhood has made my wife to go out with "small boys." She has finally packed into a young man's house where she thinks that she can be fine with sex..." (Jean, diabetes patient in Yaounde).

Furthermore, the more families of diabetes patients and people in communities question clinic guidelines, the more likely they seek some kind of traditional healing. The actions of many patients, their families, and communities only fully make sense in the light of the competing attractions of the clinic or hospital, on the one hand, and the traditional healer on the other. This depends on the definitions given to the diabetes of each individual as ascribed by the individual, health care provider, family members, and the community.

3.3. Health Care Providers. There are two types of health care providers that we consider here: biomedical and traditional health care providers.

3.3.1. Biomedical Health Care Providers. In theory, biomedical health care providers (BHCP) have the potential to educate diabetes patients about their disease. But there is little or no education tailored to particular individual needs on the grounds that too many people attend consultations each day, as exemplified by the quote below:

\footnotetext{
"...So you cannot have enough time to counsel

a patient considering the number who come.
}

You have to hurry because others are waiting outside..." (nurse in Yaounde).

The clinic's regulations are very strict and waiting time, before and after consultations, is lengthy. The clinics impose a form of discipline on patients who have no alternative but to conform whilst they are within its confines. Communication between biomedical health care providers and patients in the clinics is characterized by biomedical health care providers giving very brief one- directional instructions full of blame whereby patients are instructed to follow for their treatment. Direct BHCP-patients interactions in one-to-one consultations are to read the test and anthropometrical measurements and verify if the patient requires more drugs or an increase in the dose. Health education talks are adopted as alternatives to individual discussions against the wishes of many patients who have individual issues to address. Sensitive areas like sexual dysfunction are seldom raised because it remains generally taboo to discuss them in public, and there is no consultation space available for confidential or individual counselling.

The more senior biomedical health care providers are socialized into a biomedical approach to health care, the more they commonly neglect those facets of the experience of illness that might be considered psychosocial and cultural. Such BHCP rarely seem to understand the cluster of reasons that may pull patients away from clinics and tend to base their understanding of patients' actions only around clinical indicators and measurements made in the clinic setting. However, understandable this is, it serves to make their job of communicating with their patients about the many complications of diabetes more difficult, for figures and measurements are hard to set in context for most patients. The consequence is that more senior BHCP and patients have only a very partial grasp of each other's idioms and frames of reference.

The more the gulf in understanding between clinic staff and patients is manifested or maintained, the greater the tendency is to passivity among those patients who attend. Yet staff may not take into account that patient passivity hides various states of mind. But health care providers term this as noncompliance to biomedical regimes, "Patients make the job difficult for us because they do not comply with their treatment." Moreover, the financial costs of adhering to clinic advice are also a factor, adding to this resistance. A nurse declared, "at times they do not have the money to buy the medicines. But even those who have the money do not still comply."

3.3.2. Traditional Healers. The contribution of traditional healers (TH), their claims, and their particular perspective, on diabetes are taken very seriously. TH in Yaounde are flexible in their approaches and strategies in the process of caring for people with diabetes. They have the ability to represent themselves in many forms. They become diviners, native doctors, traditional healers, traditional doctors, soothsayers, herbalists, and spiritual healers following the circumstances that they find themselves and the calibre of people that they come across. Besides using herbs, incantations, prayers, and 
animate and inanimate products in their practice to cure diabetes, they apply divination, an aspect believed to be out of the reach of lay people. Some, like the spiritual healers, add prayers to their practice as illustrated by the quote below.

\section{“... When I consult a patient I pray with him or her. If it turns out that the patient has a problem with the family in the village, I ask him to go and reconcile before he can be cured..." (traditional healer in Yaounde).}

The reputation of many $\mathrm{TH}$ stems from the fact that they have easily adapted their practices to suit the needs of urban residents, descendants of numerous ethnic groups. Moreover, by adopting some of the traditional medical practices of other ethnic groups, blending them with their "own," traditional healers have widened their clientele and extended their repute. That has earned most of them a lot of confidence from patients and their families, especially as some try to dissociate themselves from witchcraft associations and associate with herbal treatment.

It is difficult to keep questions of treatment entirely separate from discussion of causes, for the two are closely interwoven. Some of the aetiologies have already been discussed with patients above. TH are, after all, members of the same community, heirs to the same cultural values or currents of change. The following extract from an interview with a traditional healer amplifies the different perspectives and actions:

\section{"... They can come in witchcraft and put diabetes in your body when you are sleeping. . It can also happen when a family installs a wrong successor. The ancestors immediately make people in the family to be sick with diabetes. But, if the family decides to install the right successor afterwards, the diabetes will finish... Of what help is Mimbo (alcohol)? It only brings sick." (traditional healer in Bafut)}

The extract considers three main approaches to diagnosing the causes and curing diabetes. The first identifies diabetes as the consequence of witchcraft. Tackling it means identifying and neutralising the source of witchcraft. The second attributes diabetes to the sphere of kinship and damaged social relations-often quite unwitting and unrecognizedamong kin. Succession is the crux here, and relations between the living and ancestors are the focus of restorative action. The third focuses attention on individual eating and drinking habits, lifestyle in the idiom of western public health, though that concept does not mean a great deal to the majority of people in Cameroon.

3.3.3. Healer Treatment Networking. Some traditional healers use health facilities to confirm diagnosis as illustrated by the following quote:

"I do not have a machine to diagnose that you have diabetes, so when I cannot divine it here, I send you to the hospital. When I cure you I refer you to

\section{the hospital so that they measure your sugar to see if it has finished." (traditional healer in Yaounde)}

The above quote illustrates the type of networking that traditional healers engage in to confirm diagnosis and treatment when they are treating patients. Healers use their local knowledge and technologies of divination, herbal remedies, and rituals to treat people with diabetes. To show their efficacy, they refer people with diabetes to consult health facilities for laboratory test. If results show that the glucose level has reduced, he interprets that the person has been cured and is well.

Diagnosis at the hospital reveals to the patient that the signs and symptoms he or she is suffering from is diabetes. But what it fails to explain are where the diabetes has come from and why it has affected that person and not another. In some cases, traditional healers' knowledge of some of the signs and symptoms helps them to diagnose that a person has diabetes. A traditional healer who refers a patient to a health facility for the confirmation of diagnosis does this only when he is very sure that his diagnosis would not fail. But there are situations where some traditional healers would say:

"When I cure you for witchcraft or make peace with the ancestors, we may continue the treatment to cure your diabetes. If I see that it is only the hospital that can treat your diabetes, I send you to see a doctor, if not then I cure you here."

This networking portrays the power traditional healers have to make use and control the diabetes treatment networks around them. It assures people with diabetes that he collaborates and is tolerant of biomedicine.

Many people interpret illness attacks in Cameroon in terms of weak and strong blood. If your blood is considered as weak, you are considered to be highly vulnerable to illness attacks of any nature. If your blood is considered "strong," then you are highly immune to attacks from any illness. The concepts of weak and strong blood are also linked to vulnerability to diabetes. Having high blood means that you have a high immunity and having weak blood means you have high vulnerability to being affected by diabetes. The concept of "weak blood" and "strong blood" and the connections to low and high blood glucose levels have a prominence in interpretation, as the following quote of a traditional healer in Yaounde illustrates:

\section{“...People with weak blood are easily affected by diabetes but if you have strong blood, it will be difficult for diabetes to affect you..."}

To be told that you have "weak blood" is to be diagnosed as vulnerable. The view is held in the community that high blood is a sign of strength, so traditional healers interpret weak and strong blood from this foundation. This notion of "high blood" is not equated with hypertension but with "strong blood." It is seen as the equivalence of immunity to disease, and hence to diabetes, especially when reference is made to witchcraft. The three frames of references lead us into the triangle of diabetes care summarised in Figure 1. 


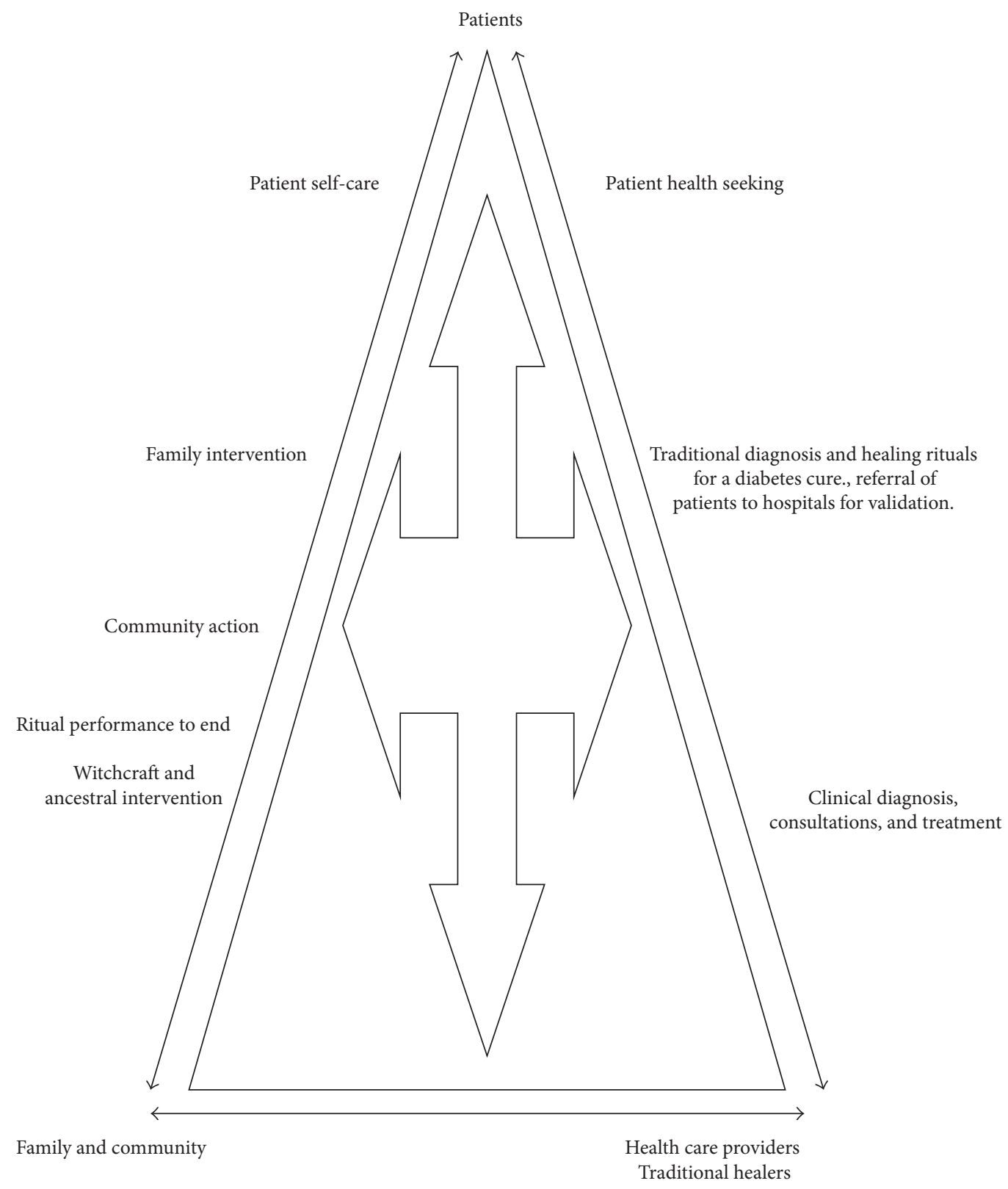

Figure 1: Adapted integrated triangle of care for diabetes in Africa.

Figure 1 presents an integrated triangle of care for diabetes. This triangle of care is adapted from the WHO Integrated Chronic Care Model. The direction of arrows shows the path taken by people with diabetes when they are seeking care. The path is not straightforward but a forward and backward movement as shown by the arrows. When a person is affected with diabetes, he may take the initial treatment decision. Subsequent decisions are taken by the family and at times by the community at large. The family and community may decide one or all of the following available treatment options linked to biomedicine and traditional medicine: clinic attendance and clinic-based care and divination plus ritual performances and herbal treatment. The healers they will meet in their treatment arena will be biomedical and traditional.
The difference between the adapted triangle of care derived from this study and that of WHO is that this adapted integrated triangle of care for diabetes includes traditional healers, traditional medicine, and traditional treatment in the treatment network while that of WHO excludes them.

\section{Discussion}

In all countries, the lives of patients with chronic diseases extend far beyond the barriers of formal clinics and the reach of health care teams. Moreover, communities can provide services that complement and support the care provided in health care organisations bridging the service gap between the organised clinical care and the real world of patients. Little is reported about the requirements of implementing an 
adapted integrated patient centred care model in the African context (see Figure 1 for the adapted integrated triangle of care for diabetes in Africa). This model has been adapted from the WHO Integrated Chronic Care Model.

De-Graft Aikins [15] has pointed out that diabetes patients in Ghana undervalue traditional medicine and prefer biomedicine. She emphasizes that cost is the main drawback to adherence to biomedicine. This research complements hers but points out its limitations given that she did not undertake participant observation to get most of the revealing beliefs, behaviours, and contradictions that go with diabetes care. The results of this study go to confirm those of DeGraft Aikins [15] and Brewer [26] whereby patients set out to seek a cure for diabetes. Though De-Graft Aikins [15] concluded that patients trusted biomedicine more than traditional medicine, this study illustrates that traditional medicine is highly valued the same as biomedicine is and that the language of biomedicine is not convincing enough because it proposes control and not a cure for diabetes. Our research complements that of De-Graft Aikins' work in Ghana [15].

This paper explicitly looks precisely at the relationships and dynamics of a network of actors through participating in their lives. De-Graft Aikins [15] tends to say patients in Ghana knew that traditional medicine was inferior to biomedicine and that cost was the real inhibiting factor. But it is not just cost that inhibits the success of biomedicine but also many patients and their families still find it more convincing to combine biomedical and "traditional" causal explanations and therapies because the notions of the body and its vulnerability are more familiarly understood in relation to traditional grounded diagnoses for a start.

De-Graft Aikins [15] had indicated that the healer shopping behaviour of patients is more eminent in rural than urban areas. But according to this ethnography, people with diabetes in urban areas reach out for much more healing options than their rural counterparts. The alternative adventure becomes more magnified in urban areas as people seek out various ways of making use of the variety of healing options available in towns, whereas in villages patients have limited options.

4.1. Adapting and Adopting an Integrated Patient Centered Care Model in Diabetes Care. Patients' knowledge and interactions with alternative therapeutic options indicate inadequacies in biomedical approach to diabetes care to fill the knowledge gap and keep the patients within their confines, trust, and confidence [14, 27, 28]. This suggests an area of unmet needs: that of empathy and cultural insights and belonging in public health, otherwise provided by traditional healers. For that reason, biomedical professionals in Africa may review their present approach to biomedicine, $[13,14]$ understand the innovative chronic care framework, and adapt to psychosocial skills of traditional healers in their consultations $[12,14,29]$. In this way, patients' misuse and patients' loss to follow up and development of complications as a result of interference from outside the biomedical treatment network may be minimised. Awah [12] had suggested an inclusive approach that will include traditional healers as healers that provide the psychological and social aspect of health that may not be easily possible with biomedicine in Africa. Another publication [14] explained the need for biomedical professionals to consider the views of patients about their disease to optimize adherence to biomedical treatment of diabetes.

Patients and families seem to have high expectations of traditional medicine $[14,30]$, assuming that such therapy is inherently linked to a holistic approach and a therapeutic relationship that has been built on trust and support. Hence, their exception is that they should be considered as a complex whole rather than just the physical wellbeing that they are subsumed to. Communication, understanding, empathy, and respect of their own opinions and beliefs are issues, which patients [31-33] and families think are worthy of harnessing. Though the effectiveness of traditional medicine is questionable, its psychosocial impact cannot be underestimated in influencing the return of patients to clinics. This study suggests that patients and families have high expectations of traditional medicine; however, the relationship between these expectations and therapeutic outcomes is unmeasured territory that necessitates detailed exploration using quantitative tools to rank issues by importance of their expectations.

Behaviour change is difficult to initiate and sustain, and the reasons why efforts to promote healthy behaviour fail have been explored in this paper as has been scrutinised by others $[7,9,15]$. To be successful, health interventions should build on existing practices, skills, and priorities and recognise the constraints on human behaviour and either feature community mobilisation or target those most receptive to change. Furthermore, interventions for chronic conditions like diabetes should strive to be "culturally impelling" [34] and "culturally inclusive" $[7,12,30]$ not merely culturally appropriate: they must engage local communities and nestle within social and ecological landscape [34]. A culturally inclusive intervention is one which people from different cultures acknowledge as an intervention as a part of their own activity in the community in which they live. Such a sense of ownership can only be developed through the active and visible participation of community members in the intervention at all levels, not just as consumers of a service. A culturally compelling health intervention is when the behavior of people is compelled into action to improve treatment outcomes because they believe that they have ownership of the intervention and participate in setting priorities.

Interventions based on the patient centred model may enable physicians to intervene in a patient centred manner $[29,30]$ and patients will comply better and improve their blood glucose outcomes. A more patient centred approach presumably preserves the expectancy of freedom and control, which is crucial in preventing psychological and social reactance and enabling adherence to biomedical care for diabetes [35]. But the patient centred care has to be culturally inclusive and compelling to make an impact, therefore necessitating an Integrated Chronic Care Model to diabetes and other conditions. 
Though this study has used the ethnographic approach to study diabetes in Cameroon, the study limits itself to two sociocultural ecologies of Cameroon-the Forest and Grassfield ecologies. It is likely that these findings may not strictly apply to the other two ecologies (Coastal and Sahel). However, the findings are useful in informing policy makers on issues about cultural interpretation of illness and disease and the alternative perspectives of care for chronic diseases. To add more evidence to these findings a quantitative study design may help quantify these findings and relate them to treatment outcomes with different patterns of care.

\section{Conclusions}

This paper presents ethnography of diabetes, illustrating the role of different actors involved in treating diabetes. It ascertains the validity of the integrated clinic care model developed from the patient centred care model. The Integrated Chronic Care Model (ICCM) provides a flexible but comprehensive base on which to reconstruct health systems in Africa in accordance with local resources and demands. The ICCM stipulates that modern biomedical system needs to take into account the patients and community views to avert inherent frustrations. The triangle of care that I have adapted from the ICCM adds the aspect of traditional medicine and traditional healers as important partners to biomedicine in the care for diabetes. The fact that $\mathrm{TH}$ have started to acknowledge the efficacy of biomedicine over some aspects of TM and can provide clearance to patients to attend diabetes care units is indicative that they are capable of accepting weaknesses about their curing claims. Therefore, their role in preventing diabetes risk factors, diabetes, and diabetes complications should be acknowledged.

\author{
Abbreviations \\ AIDS: Acquired immune deficiency syndrome \\ BHCP: Biomedical health care providers \\ HIV: Human immunodeficiency virus \\ ICCM: Innovative care for chronic conditions \\ TH: Traditional healers \\ TM: $\quad$ Traditional medicine \\ WHO: World Health Organisation.
}

\section{Conflict of Interests}

The author declares that there is no conflict of interests regarding the publication of this paper.

\section{Acknowledgments}

The author gratefully acknowledges the contribution of the research participants in making this study possible. The author would like to thank Professor Peter Phillimore and Professor Nigel Unwin for their guidance of this research and the continued mentoring that they provide. The author is grateful to the North-East Diabetes Trust, the International
Diabetes Federation, World Diabetes Foundation, and Newcastle University which provided funding for the Ph.D. on which this paper is based. The author particularly thanks Professors George Alberti and Jean-Claude Mbanya and Mrs Hazel Glass for their inputs in enabling this research to go to a successful end.

\section{References}

[1] N. Unwin, P. Setel, S. Rashid et al., "Noncommunicable diseases in sub-Saharan Africa: where do they feature in the health research agenda?" Bulletin of the World Health Organization, vol. 79, no. 10, pp. 947-953, 2001.

[2] T. J. Aspray, F. Mugusi, S. Rashid et al., "Rural and urban differences in diabetes prevalence in Tanzania: the role of obesity, physical inactivity and urban living," Transactions of the Royal Society of Tropical Medicine and Hygiene, vol. 94, no. 6, pp. 637-644, 2000.

[3] J. A. Shu, R. Kamadjeu, E. C. Kiawi, and J. C. Mbanya, "Applying the WHO STEPS approach in a resource-limited country: the Cameroon burden of diabetes study," Diabetologia, vol. 47, supplement 1, pp. 1-8, 2004.

[4] World Health Organization, "Diabetes," Fact Sheet 312, World Health Organization, Geneva, Switzerland, 2013.

[5] IDF Diabetes Atlas, International Diabetes Federation, 6th edition, 2013.

[6] M. van Vugt, R. Hamers, O. Schellekens, T. Rinke de Wit, and P. Reis, "Diabetes and HIV/AIDS in sub-Saharan Africa: the need for sustainable healthcare systems," Diabetes Voice, vol. 52, no. 3, pp. 24-23, 2007.

[7] P. K. Awah, A. P. Kengne, L. L. K. Fezeu, and J. Mbanya, "Perceived risk factors of cardiovascular diseases and diabetes in Cameroon," Health Education Research, vol. 23, no. 4, pp. 612620, 2008.

[8] World Health Organization, The World Health Report 2000Health Systems: Improving Performance, World Health Organization, Geneva, Switzerland, 2000.

[9] K. M. Venkat Narayan, P. Zhang, A. M. Kanaya et al., "Diabetes: the pandemic and potential solutions," in Disease Control Priorities in Developing Countries, D. T. Jamison, J. G. Breman, A. R. Measham et al., Eds., pp. 591-604, World Bank, Washington, DC, USA, 2nd edition, 2006.

[10] E. C. Green, AIDS and STDs in Africa: Bridging the Gap between Traditional Healing and Modern Medicine, Westview Press, 1994.

[11] G. Bodeker, D. Kabatesi, R. King, and J. Homsy, "A regional task force on traditional medicine and AIDS," The Lancet, vol. 355, no. 9211, p. 1284, 2000.

[12] P. Awah, "Diabetes and traditional medicine in Africa," Diabetes Voice, vol. 51, no. 3, pp. 24-26, 2006.

[13] P. K. Awah, N. C. Unwin, and P. R. Phillimore, "Cure or control: complying with biomedical regime of diabetes in Cameroon," BMC Health Services Research, vol. 8, no. 1, article 43, 2008.

[14] P. K. Awah, N. C. Unwin, and P. R. Phillimore, "Diabetes mellitus: indigenous naming, indigenous diagnosis and self-management in an African setting: the example from Cameroon," BMC Endocrine Disorders, vol. 9, article 5, 2009.

[15] A. De-Graft Aikins, "Healer shopping in Africa: new evidence from rural-urban qualitative study of Ghanaian diabetes experiences," British Medical Journal, vol. 331, no. 7519, pp. 737-742, 2005. 
[16] World Health Organization, Innovative Care for Chronic Conditions, World Health Organization, Geneva, Switzerland, 2001.

[17] J. E. Epping-Jordan, S. D. Pruitt, R. Bengoa, and E. H. Wagner, "Improving the quality of health care for chronic conditions," Quality \& Safety in Health Care, vol. 13, no. 4, pp. 299-305, 2004.

[18] R. M. Davis, E. H. Wagner, and T. Groves, "Managing chronic disease," The British Medical Journal, vol. 318, no. 7191, pp. 10901091, 1999.

[19] R. F. Ellen, Ethnographic Research: A Guide to General Conduct, Academic Press, London, UK, 1984.

[20] M. Hammersley and P. Atkinson, Ethnography Principles in Practice, Cambridge University Press, London, UK, 1990.

[21] H. Garfinkel, Studies in Ethnomethodology, Polity, Cambridge, UK, 1984.

[22] D. Greatbatch, C. Heath, P. Campion, and P. Luff, "How do desktop computers affect the doctor-patient interaction?" Family Practice, vol. 12, no. 1, pp. 32-36, 1995.

[23] P. Have, "Transcribing talk in interaction," in Doing Conversation Analysis. A Practical Guide, pp. 75-98, Sage, London, UK, 1999.

[24] S. Inzucchi, R. Bergenstal, J. Buse et al., "Management of hyperglycemia in type 2 diabetes: a patient-centered approach," Diabetes Care, vol. 35, pp. 1364-1379, 2012.

[25] R. Jayadevappa and S. Chhatre, "Patient centered care-a conceptual model and review of the state of the art," The Open Health Services and Policy Journal, vol. 4, pp. 15-25, 2011.

[26] J. D. Brewer, Ethnography, Open University Press, Buckingham, UK, 2000.

[27] A. Kleinman, The Illness Narratives: Suffering, Healing and the Human Condition, Basic Books, New York, NY, USA, 1988.

[28] E. Kiawi, R. Edwards, J. Shu, N. Unwin, R. Kamadjeu, and J. C. Mbanya, "Knowledge, attitudes, and behavior relating to diabetes and its main risk factors among urban residents in Cameroon: a qualitative survey," Ethnicity and Disease, vol. 16, no. 2, pp. 503-509, 2006.

[29] G. N. Mbeh, R. Edwards, G. Ngufor, F. Assah, L. Fezeu, and J. Mbanya, "Traditional healers and diabetes: results from a pilot project to train traditional healers to provide health education and appropriate health care practices for diabetes patients in Cameroon," Global Health Promotion, vol. 17, no. 2, pp. 17-26, 2010.

[30] P. K. Awah and P. Phillimore, "Diabetes, medicine and modernity in Cameroon," Africa, vol. 78, no. 4, pp. 475-495, 2008.

[31] P. Ley, Communicating with Patients. Improving Communication, Satisfaction and Compliance, vol. 4 of Psychology and Health Series, Chapman \& Hall, London, UK, 1988, Edited by D. Marcer.

[32] P. Ley, "Doctor-patient communication: some quantitative estimates of the role of cognitive factors in non-compliance," Journal of Hypertension, Supplement, vol. 3, no. 1, pp. S51-S55, 1985.

[33] N. M. Clark and M. Gong, "Management of chronic disease by practitioners and patients: are we teaching the wrong things?" British Medical Journal, vol. 320, no. 7234, pp. 572-575, 2000.

[34] C. Panter-Brick, S. E. Clarke, H. Lomas, M. Pinder, and S. W. Lindsay, "Culturally compelling strategies for behaviour change: a social ecology model and case study in malaria prevention," Social Science \& Medicine, vol. 62, no. 11, pp. 2810-2825, 2006.

[35] R. Cameron and J. A. Best, "Promoting adherence to health behavior change interventions: recent findings from behavioral research," Patient Education and Counseling, vol. 10, no. 2, pp. 139-154, 1987. 

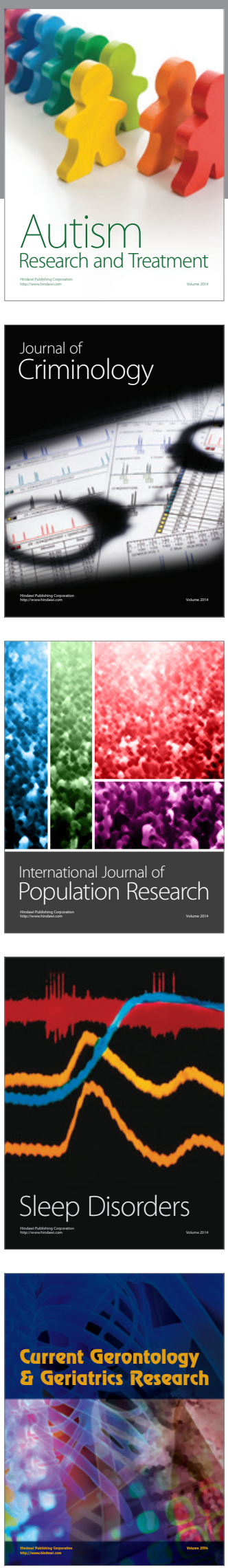
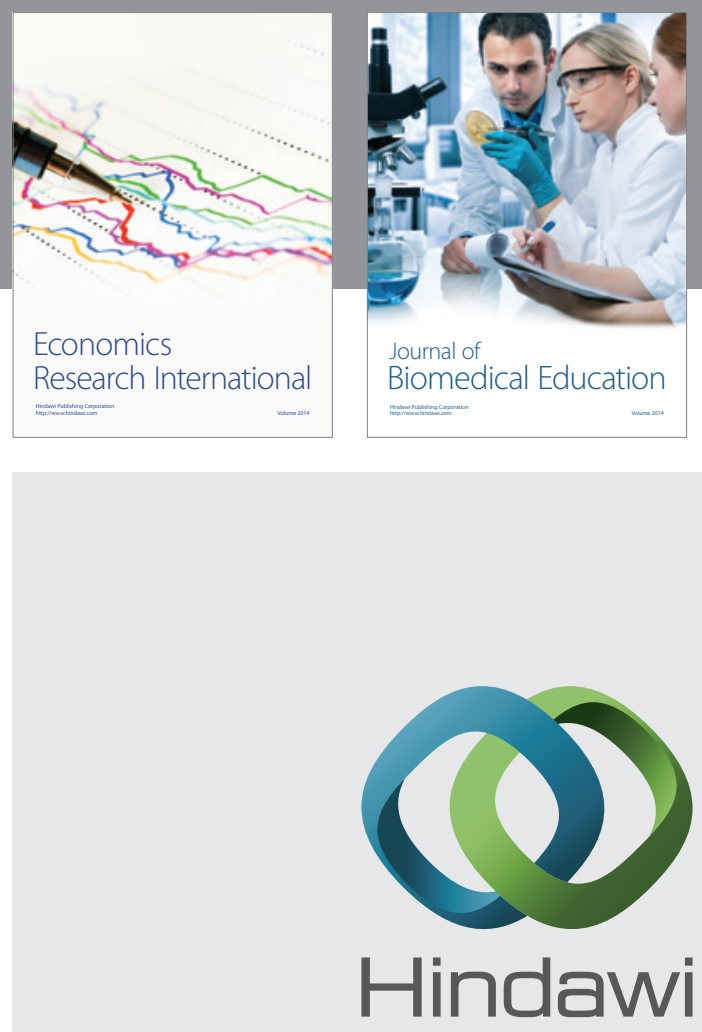

Submit your manuscripts at

http://www.hindawi.com
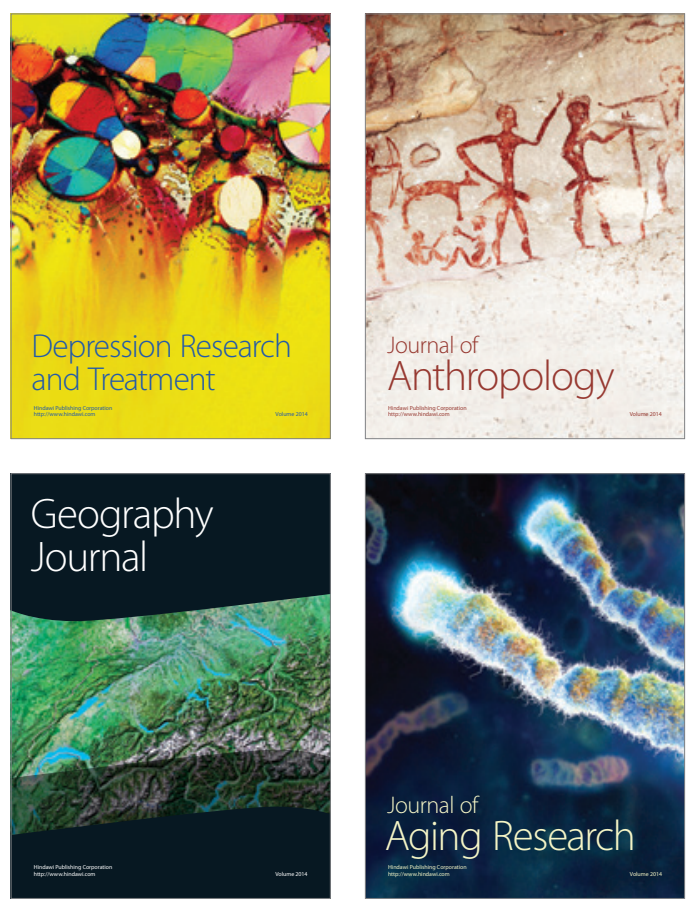
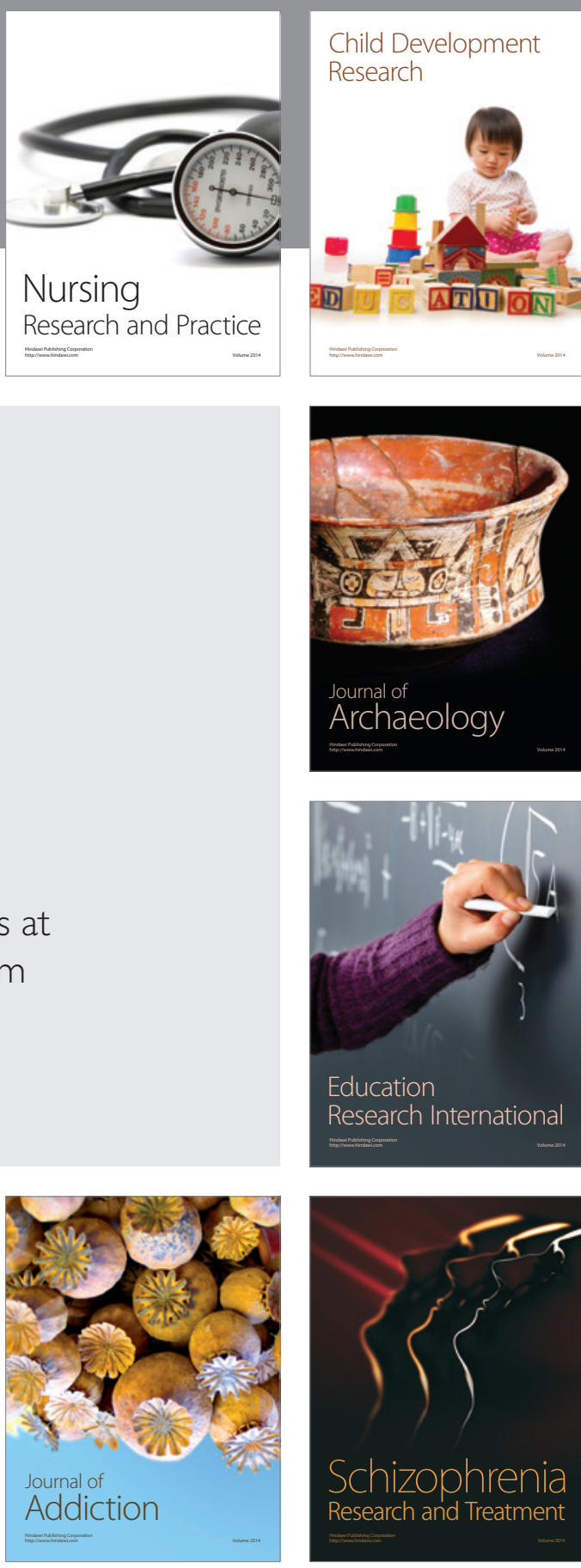

(D)
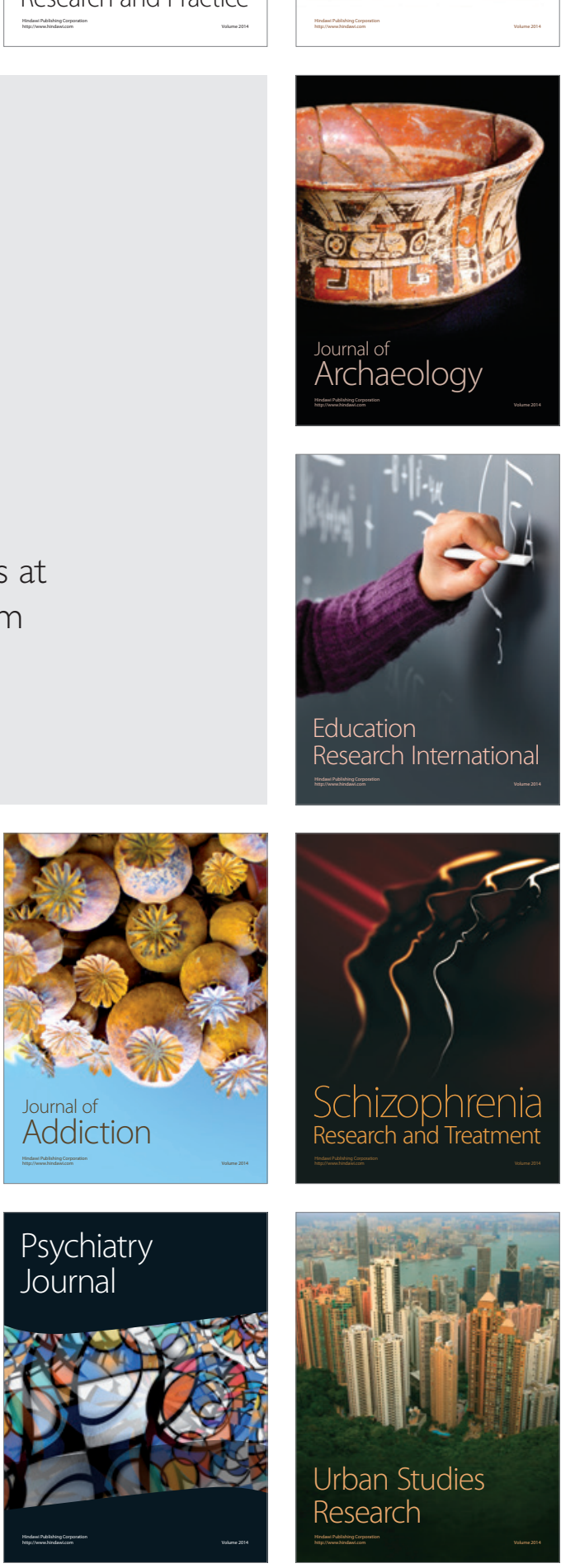